\title{
SURGERY OF THE PANCREAS.
}

\author{
By T. HOLMES SELLORS, D.M., M.Ch.(Oxon.), F.R.C.S.,
}

(Surgeon to Queen Mary's Hospital for the East End, and The London Chest Hospital, etc.).

The average attitude of surgery towards the pancreas may well be epitomised by a quotation trom a well-known French author- "Le pancréas, et c'est une raison pour laquelle il est peu ou mal exploré, est un organe profond, . . . et masqué par des organes plus superficiels". Its occasional vigorous reaction to interference or infection cause it to be treated with deference and deliberate attack on its substance can only be made with considerable care. The gland has to be considered as a highly vascular structure of two functions:-its external secretion of digestive juices into the small bowel ; and the internal secretion of the Islets of Langerhans, the significance of whose control of sugar metabolism in the body has only recently received adequate attention. From the standpoint of surgical anatomy the relationship of the head of the gland to the common bile duct and duodenum is the most important, while the proximity of the stomach, spleen and splenic vessels merit consideration.

\section{Acute Pancreatitis.}

In acute inflammatory conditions the digestive ferments rather than the bacteria are responsible for most of the dramatic changes that occur and may be referred to as a state of biochemical explosion. The essential feature of the "inflammation" consists of conversion of trypsinogen into active trypsin which digests further glandular tissue in addition to the surrounding structures. Further active ferments are liberated, among them lipase (steapsin), acting on fat tissue with which it may come in contact to produce glycerine and fatty acid. This latter by combination with calcium forms white soapy nodules, constituting the fat necrosis which is so characteristic of the disease.

To go back further and investigate the cause of the conversion of trypsinogen within the gland substance is to open up the vexed question of ætiology. Physiologically the ferment can only be activated by contact with intestinal enterokinase and this would necessitate a theory based on ascending spread or infection of the pancreatic ducts by intestinal secretion, a supposition that cannot be supported in every case. Quantities of experimental work have been produced in endeavouring to determine the ætiology of acute pancreatitis, and it would appear that bacterial infection in some instances can effect the trypsinogen activation. Explanations based on reflux of infected bile have more in their favour than theories suggesting infection by vascular and lymphatic channels.

The differentiation of pancreatitis into hæmorrhagic, apoplectic, necrotic or gangrenous forms is probably an arbitrary one, since they seem to be stages of the same condition. The clinical severity of the condition is, however, very variable, and ranges from a state so devastated by shock that surgical intervention is impossible to cases in which the symptoms are not much greater than those in an attack of cholecystitis.

The shock phenomena are understood more readily when the proximity of the solar plexus and peritoneum is realised. In addition to this the freed secretions produce an aseptic peritonitis, as witnessed by the extent of œdema found 
at operation, and paralysis of the upper bowel is a feature secondary to this. The

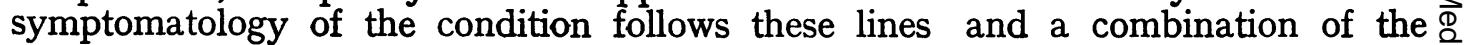
symptoms of ulcer perforation and high gut obstruction without the definite $c$. physical signs of either serves to summarise the average case. It seems also cer- $\overrightarrow{\vec{s}}$ tain that the blood electrolytes undergo gross disturbance and this is a factor that contributes to the severity of the condition.

Recently there has been considerable advocacy of the conservative treatment $\stackrel{\AA}{\alpha}$ of the disease in view of the poor results that follow operative measures (the mortality is generally given as lying between 30 and 40 per cent). There is certainly a good deal to be said in favour of this course with the definite proviso that there is no doubt as to the accuracy of the diagnosis.

Considerable reliance can be placed on a raised urinary diastase which may reach the figure of two hundred units (normal seven to thirty) and other bio- $\vec{A}$ chemical tests, but there is such an element of uncertainty in some cases that no surgeon would be prepared to chance missing a perforated ulcer or high intestinal obstruction by postponing operation.

If active treatment is practised there is no absolute clear-cut decision as to what is to be done: it depends so much on the condition of the patient. Two factors, however, can be considered :-

I. Drainage of the gland itself.

2. Treatment of the gall-bladder and biliary apparatus.

After opening the abdomen the gland is approached through the gastro-colic omentum, and the writer has found it most advantageous to do an anterior 8 splanchnic injection of novocaine at this stage. The shock appears to be relieved $\overrightarrow{\overrightarrow{0}}$ to a marked extent and the condition of the patient improved.

Bloody or discoloured turbid fluid is mopped out and the gland field drained, but the practise of making incisions over the gland to relieve tension and help drainage is not satisfactory or safe on account of the risk of hæmorrhage and of liberating further digestive ferments. If the patient recovers, the possibility of the formation of large infected sloughs necessitate a free exit and instead of drain- $\delta$ ing across the peritoneum a wide opening in the left loin in front of the kidney keeps the drainage extra-peritoneal.

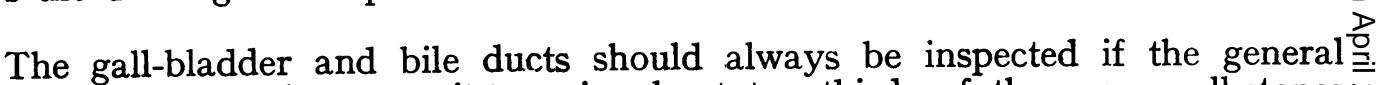
condition of the patient permits as in about two-thirds of the cases gall-stones $N$ are present. Most simply the stones are removed and the gall-bladder drained, but if circumstances permit cholecystectomy should be performed and the common bile duct explored and drained by a T-tube.

The question of mortality may best be summarised by stating that the fulminating, or as American authors call them-hyperacute, cases usually end fatally. Subacute cases on the other hand mostly recover, and between these extremes 0 there are the classical acute group of cases in which the chances of recovery are almost even. 


\section{Operative Injury.}

Operations, on the upper abdomen may in certain instances result in injury to the pancreatic tissue, sometimes without ill effect, but occasionally with fistula formation or even acute necrosis. Deep penetrating gastric or duodenal ulcers which show surrounding fibrosis and invasion of the pancreas may not be capable of excision without injury to the gland tissue. It is probably wiser in these cases to cut round the ulcer so as to leave its base intact on the pancreas. Even cauterisation or application of pure carbolic to this area has been known to cause trouble.

Another area that is a potential source of danger in gastric resection is the duodenal stump, which if not carefully freed from its extensive vascular attachment to the head of the pancreas may include pieces of glandular tissue in the suture line. Carelessly placed stitches in this region may be responsible for leakage of the duodenal stump at a later date.

Attempts at radical removal of carcinoma of the stomach are even more possible sources of danger. In attempting to go wide beyond a suspicious area it may be necessary to include part of the gland in the resected mass. On two occasions I have deliberately resected about half the head of the pancreas which was involved in a pyloric growth without ill-effect, and one of the patients is still alive and well five years after operation. On the other hand the damage lays the train for. disaster which is enhanced by the poor healing capacity of this type of patient.

Splenectomy is another field in which the pancreas may be injured. The tail of the gland may be clamped or ligated as the hilum is being secured, and as a result abscess or pseudo-cyst formation may occur. Thrombosis starting in the splenic vein and spreading to the portal vein has also been attributed to this cause.

To mention involvement of the pancreas during nephrectomy does not appear to indicate fortunate surgery, but since instances have been quoted the possibility must be recognised.

\section{Pancreatic Fistula.}

The main fear that arises from the presence of any external fistula from the gland is that of digestion of the skin and superficial tissues to leave a widely excoriated and painful gaping wound.

The distressing condition of a case that has not been carefully treated need hardly be emphasised - the extreme pain of a self-digested abdominal wall and the raw skin surface are sufficient evidence.

However, careful handling in the early stages should largely avoid this, and in many instances spontaneous closure can be obtained. A tube fitting fairly closely into the wound should lead into a bottle and thus avoid contact of the bulk of the juices with the skin and dressings. The edge of the opening is painted with mastisol and a wide piece of sheet rubber made adherent to the skin as close to the opening as possible. Vaseline or some mineral (rather than a fatty) oil or grease can be packed thickly on any area of skin to which leaking juices can obtain access. Meat extracts have also been advocated to make a barrier on which the ferments expend themselves before reaching the skin. Dilute acetic and carbolic acid are also recommended on the grounds that they may help to neutralise the alkalinity of the secretion. 
Once control of the fistula has been established suction may be applied to the tube and maintained as long as possible. It is interesting to note that an extensive fistula may secrete as much as one to two pints a day.

As regards dietary it has been shown that a low carbohydrate and high fat intake help to reduce the amount and activity of the secretion. Alkalis are also held to be advantageous, but atropine and refeeding of the juice to the patient do not appear to be of any great value.

\section{Cysts of the Pancreas.}

True cysts of the gland are more curiosities than anything else, but pseudocysts as a result of old injury or inflammation afford great interest from the diagnostic point of view, since they appear in almost any part of the abdomen. They are often cysts of the lesser peritoneal sac. The chances of being able to remove one of these false cysts intact are small on account of its adherent base. Consequently the best course is to marsupialise the cyst on to the abdominal wall taking care to protect the skin. A fistula for some time is inevitable, but the relative or complete absence of destructive enzymes does not make it a very formidable proposition.

Transplantation of the whole fistulous track into the stomach or small gut has been practised successfully on a few occasions.

\section{Chronic Pancreatitis.}

Chronic inflammation of the gland is usually brought to the notice of the surgeon for a chronic dyspepsia or some obstruction to the bile passage. The distinction between carcinoma and chronic inflammation cannot always be made at operation and treatment will be directed towards the biliary apparatus. Judd held that over a quarter of the patients that he operated on for gall-bladder disease showed signs of chronic pancreatitis. Treatment will therefore be directed towards drainage of bile and/or its deflection via the gall-bladder into the stomach or duodenum. If carcinoma is suspected anastomosis (cholecystogastrostomy) should be done.

\section{Carcinoma or Adenoma.}

Radical removal of a benign or malignant growth of the pancreas is rarely possible, or more correctly is rarely attempted. Successful excision of part of the whole of the gland has been performed, but in the head of the gland the proximity of the common bile duct is a deterrent. This can be overcome by making a preliminary alternative route for the bile by some form of anastomosis before attempting the actual excision. Complete excision of the head involves sacrifice of both ducts of the gland with resulting loss of the pancreatic secretion to the intestinal tract. This has been alleged to cause little disturbance, but it seems improbable that complete loss of the secretion can avoid affecting the bodily economy.

It may well be that many of the cases loosely grouped under carcinoma of the head of the pancreas include growths of the common bile duct and ampulla. Resection of the body or tail of the pancreas is clearly a more simple procedure since the question of dealing with the duct of Wirsung is not so pressing. On the occasions that this has been done it has usually been found advisable to remove the spleen in addition, since injury to the splenic vessels is highly probable. 
In any local resection of the gland the fear of surrounding tissue digestion is present and fistula formation is common, but Evarts Graham (from an experience of six cases) points out that the secretion that escapes is neither infected nor activated by enterokinase. Consequently the skin is not likely to be badly digested and the fistulæ heal readily. In closing the raw stump of the glandular tissue the tendency is to use silk sutures in preference to catgut in order to avoid the risk of suture digestion with leakage and secondary hæmorrhage.

\section{The Islets of Langerhans.}

Deficiency of the internal secretion from the islet tissue does not enter the field of surgery, except in so far as some of its remote complications require treatment. On the other hand within the past ten or twelve years the reverse-or overactivity of this tissue-has developed into a fascinating surgical problem. Adenoma or carcinoma of the islets produce a very definite syndrome which, if recognised, is often amenable to surgery. One is reminded of the similarity of the rapid increase in knowledge of hyperparathyroidism with this condition of hyperinsulinismsmall active tumours of endocrine tissue dominating from their special angles the whole picture of metabolism. The effect of this internal overdosage with insulin is to reduce the blood sugar to such an extent that hypoglycæmic symptoms appear. The control of blood sugar is not solely dependent on the pancreatic islets secreting insulin, but is affected also by the anterior lobe of the pituitary, the liver, and the suprarenals. Consequently disease of these organs has to be excluded as far as possible before attributing the persistently low blood sugar to excessive secretion of insulin. In severe cases of hyperinsulinism ingestion of several pounds of glucose a day fail to control the symptoms which take the form of "fits" or "attacks". It is not unexpected therefore that conditions which reduce the sugar reserve-such as lack of food, exercise-exacerbate the acute symptoms. Whipple, to whom with other American authorities we are mostly indebted for the pioneer work on this subject, demands that a case suitable for operation should present three main features :-

I. Attacks of nervous or gastric disturbance during a period of fasting. These take a variety of forms: faintness, twitchings, loss of consciousness, mental irritability, and confusion being common.

2. Hypoglycæmia giving a blood sugar reading of $50 \mathrm{mgm}$. per cent. or lower.

3. Rapid relief of the symptoms on eating glucose.

The results of operation are gratifying, and the removal of a small tumour of islet tissue from the substance of the pancreas results in marked improvement and in many cases of cure. Whipple reports a collection of fifty-six cases with an operative mortality of under ten per cent. and relief in a high proportion.

In some instances no tumour can be found at operation and in these the body and tail of the pancreas may be resected. In some cases the excised gland tissue is found to contain one or more small adenomata which had not been detected in the first instance; but in others the only abnormality that is present is an excess of islet tissue scattered through the gland. In this latter group the expectation of relief is roughly proportional to the degree of excess, and the results more than justify the performance of this apparently drastic operation. 